\title{
Assessment of Knowledge and Attitude of Infertile Couples About Assisted Reproductive Technology
}

\author{
Sanaa Mazeed Mohamed, Entisar Mohamed Younes, Hameda Alam El-Deen \& Ahmed Ali Abd-Elaliem \\ Nursing Specialist at center for Technical training and nursing development, Assuit University, Hospital, Egypt. \\ Assistant professor of Obstetrics \& Gynecological Nursing, Faculty of Nursing, Assiut University Egypt. \\ Assistant professor of Obstetrics \& Gynecological Nursing, Faculty of Nursing, Assiut University Egypt. \\ Lecturer of Obstetrics \& Gynecological Medicine, Faculty of Medicine, Assiut University, Egypt.
}

\begin{abstract}
Knowledge of infertile couples about Assissted Reproductive Technology is an essential parameter to improve the infertility treatment and conduct it cooperatively Aim of the present study: was to assess knowledge and attitude of infertile couples about Assisted Reproductive Technology Subject and Methods: A descriptive study design was carried out in the outpatient infertility clinic at Women's Health Hospital Assiut University, Sample: On hundred infertile couples were recruited for this study Tools: structured interview schedule about demographic data, infertility history, and several relevant variables was used to assess the knowledge and 5 point Likert scale to assess the attitude of the infertile couples regarding Assisted Reproductive Technology Results: Eighty one percent of infertile couples had inadequate knowledge and positive attitude regarding Assisted Reproductive Technology represents eighty five percent with no statistical significant differences between the knowledge of infertile couples and their socio-demographic characteristics and couple's Attitude related Assisted Reproductive Technology. Conclusion and Recommendations: infertile couples have inadequate level of knowledge towards Assisted Reproductive Technology. So the nurses in infertility clinics should premise on health education and counseling about Assisted Reproductive Technology.
\end{abstract}

Keywords: Infertile Couple's Knowledge, Attitude \& Assisted Reproductive Technology.

\section{Introduction}

Infertility is a major problem that affects men and women everywhere in the world. Although estimates of prevalence rates of infertility are not accurate, and variant among countries and different populations, Within countries, worldwide about $8 \%$ to $12 \%$ of couples experience some form of fertility problems during their reproductive life. Fifty to eighty million of the populations globally have problem with fertility. Despite the fact that infertility affects men and women, yet women, particularly of developing countries (Sones, \& Cohen 2007).

Infertility in Egypt affects 12 per cent of Egyptian couples. Of these women, 4.3 per cent suffer from primary infertility (have never been pregnant) and 7.7 per cent suffer from secondary infertility (have been pregnant before, even if the pregnancy ended in a miscarriage or an ectopic pregnancy). The number of women aged 15 to 49 years exceeds 25 million, which means that at least 3 million women are infertile in Egypt (Sallam, 2013).

Assisted reproductive technology (ART) has helped infertile couples to conceive, and to have child. According to this definition, assisted reproductive technology is defined all treatments or procedures that include the in - vitro handling of both human oocytes and sperm, or -embryos, for the purpose of establishing a pregnancy. This includes, but is not limited to, in - vitro fertilization and embryo transfer, gamete -intrafallopian transfer, zygote intrafallopian transfer, tubal embryo transfer, gamete and embryo cryopreservation, oocyte and embryo donation, and gestational surrogacy. ART does not include assisted insemination (artificial insemination) using sperm from either a woman's partner or a sperm donor (Zegers-Hochschild, et al., 2009)

The use of ART has been increasing steadily since its inception, and today slightly more than $1 \%$ of infants are born using ART. Trends indicate that the use of ART will continue to grow for some time, especially because the incidence of infertility is still high in developed nations, including the United States, and because first marriage and first birth is delayed (CDC, 2014).

Knowledge of infertile couples about assisted reproductive technology is an essential parameter to optimize the infertility treatment and conduct it cooperatively. On the other hand, different aspects of this technology lead to many serious socioeconomical and ethical problems. Particularly for those who practice reproduction techniques, it is important to learn about the various public attitudes related to parental rights, legislation and available resources for assisted reproductive technologies (ART) (Farnaz \& Mina 2005). 
This knowledge may also help wider society to understand and empathize with the infertile couple, which may lead to a decrease in the psychological burden to those affected (Bunting \& Boivin 2008) . Nurses are often the first healthcare providers that women encounter for preconception and prenatal issues. Preconception care involves the "assessment of risk factors for having a child with a genetic disorder, providing information about preconception, prenatal testing, and reproductive options to minimize the chance of having children with genetic problems." Nurses obtain the family, medical, obstetric, and genetic history, physical examination, and laboratory results which provide vital information for determining risk factors. Once the risk factors have been assessed, appropriate lifestyle modifications (ex. diet, medications, environments) can be made to optimize preconception and prenatal care (Shapira \& Dolan 2006)

\section{Significance of the study}

Assisted Reproductive technology is an excellent solution for many infertile couples who cannot conceive the desired child by other treatments. It gave hope to a lot of people all over the world to have children. Today technology makes life easier and creates a hopeful possibility. Although, this technology has changed the way we view reproduction.

From clinical experience, the knowledge and attitude of the couples about ART is not enough \& not clear. The knowledge of infertile couples about assisted reproductive technology is a fundamental parameter to optimize the infertility treatment and conduct it cooperatively. On the other hand, different aspects of this technology lead to many serious socioeconomical and ethical problems.

The quality of infertility care depends upon the awareness of the couple about the management of adequate material resources and the appropriate use of it.

The Assisted Reproductive Technology nurse plays a fundamental role in optimizing quality of care and outcomes for clients accessing ART services. The ART industry is required to function within the Reproductive Technology Accreditation Committee Code of Practice. From a nursing perspective, one of the key elements of the Code is competence in relation to the management and coordination of ART treatment cycles

In our country no previous studies have been conducted to assess the level of knowledge or the attitudes of infertile couple related to assisted reproductive technology. So, the investigator is interesting in this study to assess the infertile couple's knowledge and attitude to word ART.

\section{Aim of the study}

To assess the infertile couple's knowledge \& Attitude about assisted reproductive technology.

\section{Subjects \& methods}

This study was conducted at out patient's infertility clinic at Women's Health Hospital, Assiut University; this clinic provides services for all patients with infertility within and outside the province of Assiut governorate.

\section{Subjects}

on hundred infertile couples were recruited for this study. A convenient sample of infertile couples who attended the outpatient infertility-clinic at women's health hospital, Assiut University, was used. The sample was calculated using the Epi-Info statistical package, version 3.3 with power analysis of $80 \%$, a value of $2-5$ is chosen as the acceptable limit of precision (D) at $95 \%$ level of confidence (CI), with expected prevalence $10 \%$, and worst acceptable $25 \%$, Accordingly, sample size was estimated to be 83 infertile couples $+10 \%$ to guard against nonrespondents rate, So the total sample was 100 couples.

Inclusion criteria: Infertile couples who are willing to participate in this study. Infertile couples who were available during the period of data collection

Exclusion criteria: Any infertile women attended the outpatient clinic alone without her husband.

Tools of the study: Tools were conducted after reviewing the relevant literature and modified to assess knowledge and attitude of infertile couples about assisted reproductive technology in Women's Health Hospital at Assiut University. A structured interview schedule was developed by the researcher to collect data for this study and consisted of Items and questions as follows:

- socio-demographic characteristics of studied women which contains items such as age, level of education, marital status, family income, Occupation and residence.

- Medical history, surgical history for both couples, and types of surgery if it previously done. duration of infertility and investigations which were done for infertility to diagnosis it.

- Couple's knowledge about assisted reproductive technologies contained questions such as (what is the ART, types of ART, definitions of in vitro fertilization, of intracytoplasimic sperm injection, intrautrininsemination, investigation before IVF, which couple is suitable to do the IVF, knowledge about steps of IVF, knowledge about successful rate of IVF, suitable couples for ART, how many time can they do IVF, complications of IVF, how many embryo can be implantation, source of 
information about ART, who encourage for treat of infertility for ART).

- Scoring system for that tool was 24 degree. It was distributed according to the complexity needed for questions the score of each item summed-up and then converted into percent score, below $60 \%$ was regarded as inadequate knowledge about ART and above $60 \%$ was regarded as adequate knowledge about ART.

- Couple's Attitude about ART. This item contained (9) questions which measure the couple's attitude toward ART by using 5 items Lekert scale to scaling response of couples regarding ART. Scoring system for the couple's attitude was nine degree .The essential item took higher degree. Below $60 \%$ was regarded as negative attitude toward ART and 60\% and above was regarded as positive attitude toward ART.

\section{Pilot study}

Pilot study was carried out in August 2012, on 10 couples, they were chosen from outpatient infertility clinic to check and ensure the clarity, applicability of the tools and to estimate the time required from interview. Some minor modifications based on the result of the pilot study were made to have more applicable tools for data collection, some statements were omitted, added or rephrased, and then the final forms were developed and the subjects were not excluded from the actual study.

Felid work. Of the present study was scheduled in the following steps.

Administrative phase: - An official permission was obtained from the Dean of the Faculty of nursing, directed of the manger of women's Health Hospital, the purpose and nature of the study was explained for taking their approval to carry out the study.

\section{Ethical considerations}

The ethical clearance is obtained from the research committee at Faculty of Nursing Assuit University.

Before the initial interview, a written consent was obtained from each couple after being informed about the nature, purpose and benefits of the study. Patients were also informed that participation is voluntary and they have the right to withdraw at any time without giving reasons. Confidentiality of any obtained information was ensuring through coding of all data and reassured couples that the data would be used for only the research purpose.

\section{Procedure}

The researcher introduced herself to the infertile couple and briefly explained the nature of the study and interviewed the couple face to face to fill questionnaire at the outpatient infertility clinic Filling of questionnaire took about 25 -30minutes from each couple
Then the researchers interviewed the couples and taking their personal data and complete the sheet and answer the questions to assess their knowledge \& attitude toward ART.

The study was conducted in eight months; starting from August 2012 and ended in March 2013; Data was collected one day / week according to the infertility outpatient clinic and hospital rules .The investigator assured voluntary participation and confidentiality of each couple who agreed to participate.

\section{Statistical analysis}

The collected data was coded, tabulated and analyzed using Statistical Package for Social Science (SPSS) version 16 windows Microsoft descriptive and inferential statistics were calculated.

Data were presented using descriptive statistics in the form of frequencies and percentages for qualitative variables. Significance was considered at $\mathrm{p}$ value < 0.05

Multiple regression analyses were run to assess the effect of the independent variables (couple characteristics) on the dependent variable (knowledge and attitude). This test used because there is more than one independent variable The variables significance was classified as

- N.S=Non-significant at $\mathrm{p}>0.05$

*Mild significant at $\mathrm{p}<0.05$

- **Moderate significant at $\mathrm{p}<0.01$ ***Highly significant at $\mathrm{p}<0.001$

\section{Limitation}

- It was so difficult for some patients attended at the clinic with her husband's and they were not included of the study.

- The clinic works one day a week. So data collection time was extended to eight months to be completed. 


\section{Results}

A total of 100 infertile couples participated in this survey

Table (1): Socio-demographic characteristics of infertile couples.

\begin{tabular}{|c|c|c|c|c|}
\hline \multirow{2}{*}{ Items } & \multicolumn{2}{|c|}{ Wife } & \multicolumn{2}{|c|}{ Husband } \\
\hline & No. (100) & $\%$ & No. (100) & $\%$ \\
\hline \multicolumn{5}{|l|}{ Age } \\
\hline $20-30$ & 57 & 57.0 & 19 & 19.0 \\
\hline $31-45$ & 43 & 43.0 & 75 & 75.0 \\
\hline $46-60$ & - & - & 6 & 6.0 \\
\hline Mean \pm SD (years) & \multicolumn{2}{|c|}{$29.8 \pm 6.4$} & \multicolumn{2}{|c|}{$36.4 \pm 7.2$} \\
\hline \multicolumn{5}{|l|}{ Level of education } \\
\hline Illiterate & 45 & 45.0 & 31 & 31.0 \\
\hline Read and write & 13 & 13.0 & 19 & 19.0 \\
\hline Secondary education & 37 & 37.0 & 44 & 44.0 \\
\hline University education & 5 & 5.0 & 6 & 6.0 \\
\hline \multicolumn{5}{|l|}{ Working } \\
\hline Employed & 12 & 12.0 & 96 & 96.0 \\
\hline Not employed & 88 & 88.0 & 4 & 4.0 \\
\hline \multicolumn{5}{|l|}{ Marital status for both couples } \\
\hline First Marriage & \multicolumn{4}{|c|}{97} \\
\hline Second Marriage & \multicolumn{4}{|c|}{3} \\
\hline \multicolumn{5}{|l|}{ Family income } \\
\hline Able to do ART & \multicolumn{4}{|c|}{61} \\
\hline No able to do ART & \multicolumn{4}{|c|}{39} \\
\hline \multicolumn{5}{|l|}{ Residence } \\
\hline Rural & \multicolumn{4}{|c|}{72} \\
\hline Urban & \multicolumn{4}{|c|}{28} \\
\hline
\end{tabular}

Table (2): Relationship between infertile couples' knowledge about assisted reproductive technologies and socio-demographic characteristics.

\begin{tabular}{|c|c|c|c|c|c|c|c|c|c|}
\hline \multirow{3}{*}{ Items } & \multicolumn{4}{|c|}{ Wife } & \multicolumn{4}{|c|}{ Husband } & \multirow{3}{*}{ P-value } \\
\hline & \multicolumn{2}{|c|}{$\begin{array}{c}\text { Inadequate } \\
\text { knowledge } \\
(\mathbf{n}=81)\end{array}$} & \multicolumn{2}{|c|}{$\begin{array}{c}\text { Adequate } \\
\text { knowledge }(n= \\
\text { 19) }\end{array}$} & \multicolumn{2}{|c|}{$\begin{array}{c}\text { Inadequate } \\
\text { knowledge } \\
(\mathrm{n}=80)\end{array}$} & \multicolumn{2}{|c|}{$\begin{array}{c}\text { Adequate } \\
\text { knowledge } \\
(\mathbf{n}=\mathbf{2 0})\end{array}$} & \\
\hline & No. & $\%$ & No. & $\%$ & No. & $\%$ & No. & $\%$ & \\
\hline \multicolumn{9}{|l|}{ Age } & \multirow{4}{*}{0.612} \\
\hline $20-30$ years & 50 & 87.7 & 7 & 12.3 & 16 & 84.2 & 3 & 15.8 & \\
\hline $31-45$ years & 31 & 72.1 & 12 & 27.9 & 58 & 77.3 & 17 & 22.7 & \\
\hline $46-60$ years & 0 & 0.0 & 0 & 0.0 & 6 & 100.0 & 0 & 0.0 & \\
\hline \multicolumn{9}{|l|}{ Level of education } & \multirow{5}{*}{0.425} \\
\hline Illiterate & 41 & 91.1 & 4 & 8.9 & 26 & 83.9 & 5 & 16.1 & \\
\hline Read and write & 9 & 69.2 & 4 & 30.8 & 18 & 94.7 & 1 & 5.3 & \\
\hline Secondary education & 27 & 73.0 & 10 & 27.0 & 30 & 68.2 & 14 & 31.8 & \\
\hline University education & 4 & 80.0 & 1 & 20.0 & 6 & 100.0 & 0 & 0.0 & \\
\hline \multicolumn{9}{|l|}{ Working } & \multirow{3}{*}{0.438} \\
\hline Employed & 7 & 58.3 & 5 & 41.7 & 76 & 79.2 & 20 & 20.8 & \\
\hline Not employed & 74 & 84.1 & 14 & 15.9 & 4 & 100.0 & 0 & 0.0 & \\
\hline \multicolumn{9}{|l|}{ Residence } & \multirow{3}{*}{0.521} \\
\hline Rural & 60 & 83.3 & 12 & 16.7 & 62 & 86.1 & 10 & 13.9 & \\
\hline Urban & 20 & 71.4 & 8 & 28.6 & 19 & 67.9 & 9 & 32.1 & \\
\hline
\end{tabular}

$*$ Statistical significant differences $(p<0.05)$ 
Table (3): Multiple regression and relationship between infertile couples' knowledge about assisted reproductive technologies and socio-demographic characteristics.

\begin{tabular}{|l|c|c|c|}
\hline \multirow{2}{*}{ Items } & \multicolumn{3}{c|}{ Couples } \\
\cline { 2 - 4 } & Regression & F-test & P-value \\
\hline Age & 0.178 & 3.202 & 0.612 \\
\hline Level of education & 0.177 & 3.185 & 0.425 \\
\hline Working & 0.181 & 3.307 & 0.438 \\
\hline Residence & 0.179 & 3.258 & 0.521 \\
\hline
\end{tabular}

Table (4): Multiple regression and relationship between infertile couples' attitude about assisted reproductive technologies and socio-demographic characteristics.

\begin{tabular}{|l|c|c|c|}
\hline \multirow{2}{*}{\multicolumn{1}{c|}{ Items }} & \multicolumn{3}{c|}{ Couple attitude } \\
\cline { 2 - 4 } & Regression & F-test & P-value \\
\hline Age & 0.082 & 0.664 & 0.417 \\
\hline Level of education & 0.119 & 1.414 & 0.237 \\
\hline Working & 0.155 & 2.416 & 0.123 \\
\hline Residence & 0.050 & 0.245 & 0.622 \\
\hline
\end{tabular}

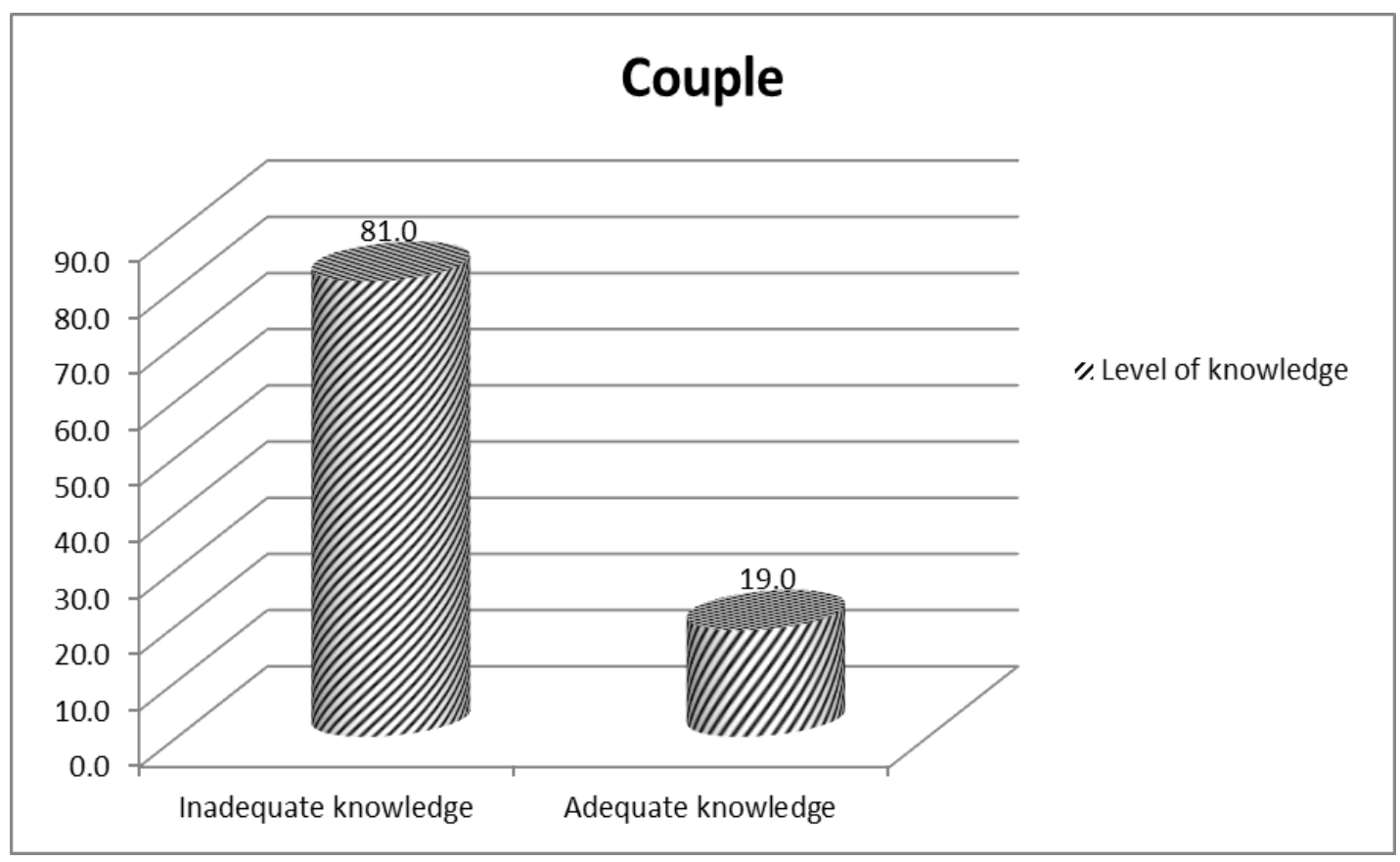

Fig. (1): Infertile couples' knowledge about assisted reproductive technologies. 


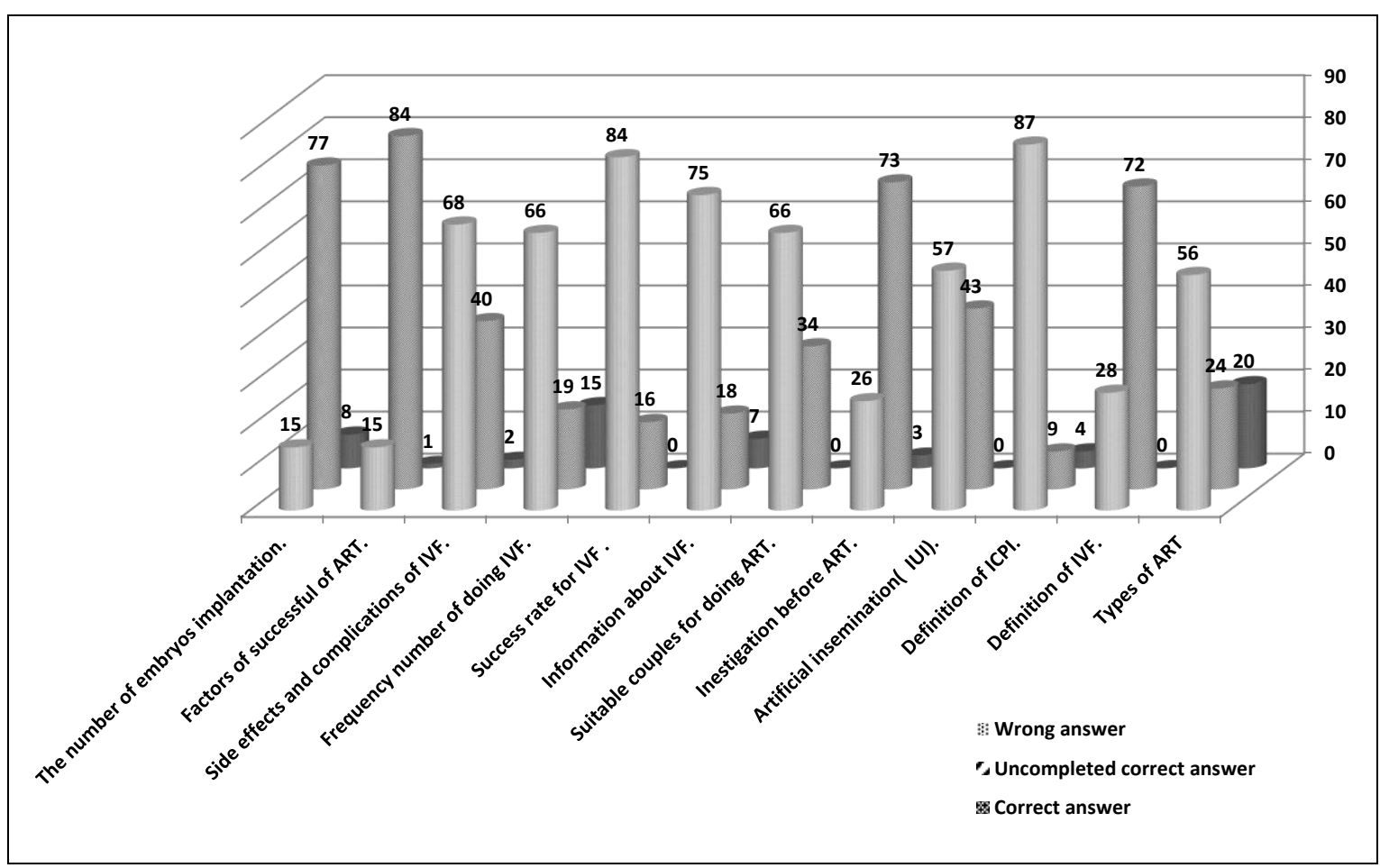

Fig. (2): Infertile couples' knowledge about assisted reproductive technologies

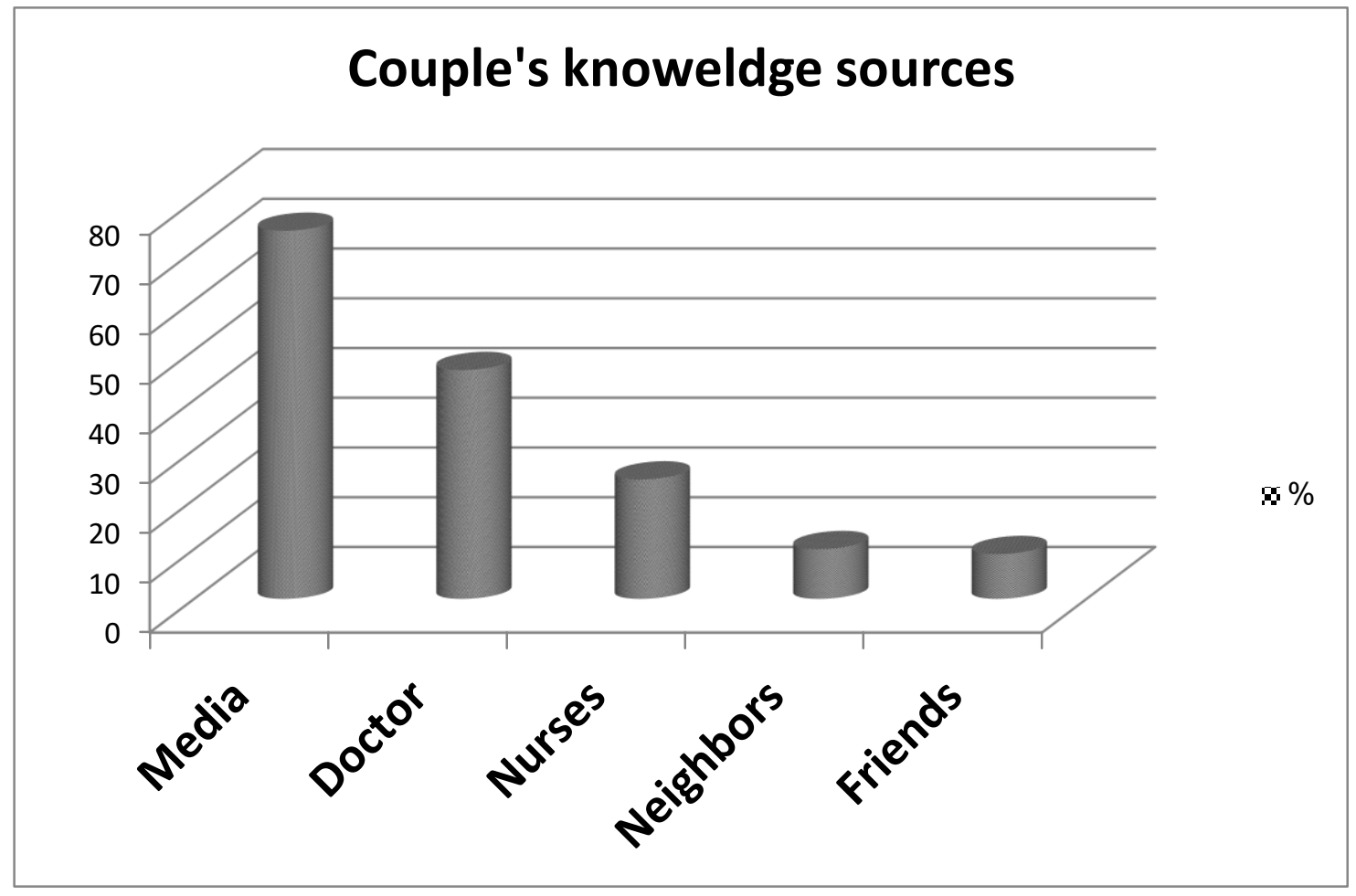

Fig. (3) Infertile couples' knowledge sources 


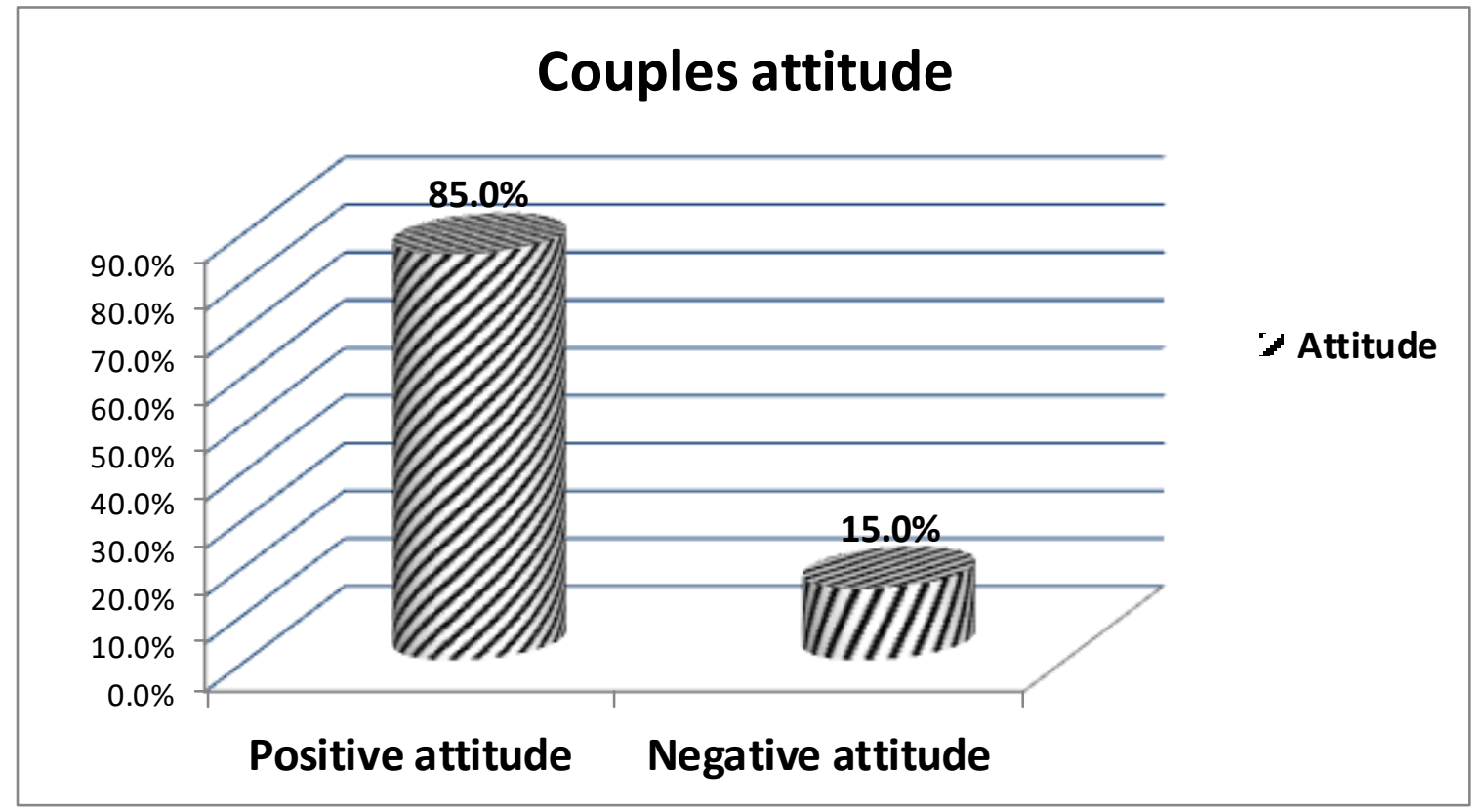

Fig. (4): Infertile couples' attitude about assisted reproductive technologies

Table (1): Related to the demographic data it shows that more than half of the wives their age ranged from 20 - 30 years in $(57.0 \%)$

And more than two thirds of couples (72.0\%) were from urban areas.

As regards the ability to do ART to get pregnancy, (61.0\%)of the studied couple able to do ART

Table (2): Shows the relationship between infertile couples' knowledge about assisted reproductive technologies and socio-demographic characteristics the couple's age of (31-45) years was associated with higher level of knowledge among both wives and their husbands. Also, higher percentages of the couples who had inadequate knowledge were illiterate and came from rural areas with no statistical significant difference between the couples

There is no significant difference between the couple as regards their knowledge about ART and socio demographic data

Table (3): This table illustrates that, there was no statistical significant differences between couple' knowledge of assisted reproductive technologies and socio-demographic characteristics. On one hand the most agents that effect on good knowledge of studied couple was (working) with regression value (0.181)

Table (4): This table illustrates that, there was no statistical significant differences between couples' attitude about assisted reproductive technologies and socio-demographic characteristics. On one hand the most agents that effect on positive attitude for studied couple was (working) with regression value (0.155).
Figure (1): Reflects that; $(81.0 \%)$ of the studied couples had inadequate knowledge about assisted reproductive technologies

Figure (2): reflects that; the infertile couples' knowledge about ART, this study explored that, the majority of studied couples had inadequate knowledge about assisted reproductive technologies in more than three quarter, with a statistically significant association found between level of knowledge and demographic.

Figure (3): Shows that; $(74.0 \%)$ of the studied couples take their knowledge from media.

Figure (4): Reflected that; vast majority of studied couples had positive attitude towards assisted reproductive technology with percentage (85.0\%) among wives and their husbands.

\section{Discussion}

Infertility is the major problem faced by reproductive age people throughout the world. Even then less focus is made on educating the couple regarding infertility and reproductive technology.

The aim of the present study was to assess the infertile couple's knowledge and attitudes about assisted reproductive technology. Research exploring the knowledge and attitude regarding infertility treatment options (ART) in Assuit university. have been carried out in Pakistan (Ali, et al., 2011).) Saudi (Abolfotouh, et al., 2012) and Bangalore by (Gundla, 2012) and other countries but very limited data is available from Egypt. With this study we hope to achieve a better understanding of the level knowledge and positive attitude toward ART. 
Infertility knowledge is inadequate in many parts of the world. A global survey of almost 17,500 women (mostly of childbearing age) from ten countries revealed that knowledge regarding fertility and the biology of reproduction was poor (Ali, et al., 2011). This finding is in agreement with the findings of the present study in which the level of knowledge was generally low, as indicated by the low mean percentage score for knowledge among the infertile couples. However, taking into account only the correct identification of the risk factors, one would conclude from the results that knowledge regarding the potential risks associated with infertility was satisfactory.

Regarding the Characteristics of the infertile Couples of this study: more than half were diagnosed as secondary infertile and more than half of them seeking treatment by own self, and according to the source of knowledge about ART, about three quarters got information about ART through media. These characteristics are nearly agreed in some items with Gundla, (2012) who described the Knowledge and Attitude of Infertile Women Regarding Assisted Reproductive Techniques at a Selected Infertility Clinic, Bangalore and reported that, the characteristics of the infertile women, more than half were in the age group of $\leq 25$ years, $42 \%$ of them had 2-4 years of marital life, $48 \%$ were educated, $58 \%$ were house wives, the family was enabling them to do ART treatment, not agree with Gundla, (2012) about three quarter of them got information about ART through health personnel, about less than half of infertile women has never conceived, and $78 \%$ were diagnosed as primary infertile.

As regarding to the infertile couples' knowledge about ART, this study explored that, the majority of studied couples had inadequate knowledge about assisted reproductive technologies in more than three quarter, with a statistically significant association found between level of knowledge and demographic variables such as education, occupation and type of infertility. Also there was no statistically significant association found between level of attitude and demographic variables such as occupation

This study revealed that the knowledge of answerers about ART was significantly related to all parameters of occupation, education, but there was no difference in knowledge between men and women. Most of infertile couple had incorrect answer about the definition of ICSI, had answer about success rate for IVF and incorrect answer about steps of IVF the lack of knowledge about ART led to there is no ART unit at Women's Health Hospital, Asyut university during the survey was done The belief of patients about the success rate of ART is an important incentive for them to count it the proper step in their treatment. In our survey, less than quarter of answerers believed the success rate of ART to be more than half of them were not aware about the rate. The findings showed that roughly most of the participants had misunderstood or ignored the information presented Knowledge about treatment option for infertility, such as IVF, is very low because it is an advanced option with limited availability in Assuit city. Also, there were no statistical significant differences between couples' knowledge of assisted reproductive technologies and socio-demographic characteristics. On the other hand the most agents that effect on knowledge of the studied couple was (working) with regression value $(0.181)$, on other hand that agent were (level of education) in husbands with regression value (0.122). In this study revealed that the knowledge of answers about ART was significantly related to all parameters of occupation and education but there was no difference in knowledge between men and women (the answer of questions are the same).This results agree with Abolfotouh, (2012) Who described the ART Knowledge, attitude, and practices of infertility among Saudi couples,poor level of knowledge (59\%) .

Regarding to attitude, findings of the present study shows that, more than half of the couples seeking for treatment from themselves with percentage. It was interesting to find that couples of the study did not want to label infertility as a 'disease'. More females $(56 \%)$ were of the opinion that infertility is not a disease as compared to males (31\%). Even though they had differing views about whether to call it a disease or not, $92 \%$ of them believed that couples should seek treatment for it.

Religion and customs continue to play a major role in the practices related to infertility. Hence, it makes sense that knowledge about treatment option for infertility, such as IVF, is very low because it is an advanced option with limited availability in Egypt. $43 \%$ considered it unacceptable because of beliefs that it's not allowed in Islam. This reveals that even the small group of people that knew about IVF is misinformed. Individuals may not be aware that IVF and similar technologies are permissible in Islam as long as they do not involve any form of third-party donation (Inhorn, 2006). Religious affiliation strongly influenced attitudes toward ART. The Public support for ART varied depending on the circumstances of its use. Education is needed to make the general community aware of the various aspects of ART. Based on the results of this study there were $(92 \%)$ of the infertile couples belief the assisted reproductive technology able to solve the infertility.

The finding of the present study shows that, there was positive couples' attitude towards means of assistance for reproduction and majority of the studied couples 
had positive attitude as regarding assisted reproductive technology with percentage $(85.0 \%)$, also, this study illustrated that, there was no statistical significant differences between couples' attitude about assisted reproductive technologies and sociodemographic characteristics. This result was agree with Gundla, (2012)The attitude of infertile woman in Bangalore toward assisted reproductive technology was positive attitude $(80 \%)$ regarding Assisted Reproductive Techniques

On one hand the most agents that effect on positive attitude for studied was (working) with regression value $(0.155)$, on other hand that agent was (level of education) in husbands with regression value (0.057). These findings were disagree with (Stephen, 1993) who studied Public attitudes in Edmonton toward assisted reproductive technology and reported that only $21 \%$ of the infertile couples had positive attitude toward agreed with public funding of ART.

Also based on the results of this study there were $(70 \%)$ of the infertile couples have negative attitude toward the magic which is the causes of infertility, This reflected that, those couples have opening minded toward the magic and this give the chance for them to seek treatment about ART to solve the infertile problems and encourages others. The less educated participants were more likely to attribute the causes of infertility to an outside human control. In fact, these findings are confirmed by another study which was conducted amongst the Kuwait infertile women (Fido, 2004) Emotional distress in infertile women in Kuwait. It was discovered in that study that the uneducated group attributed the causes of their infertility to supernatural causes such as evil spirits, witchcraft and God's retribution, while the educated group held nutrition, marital and psychosexual factors responsible for their infertility. This result was supported by results of the based on the finding results in this study there were poor knowledge about ART among the nurses, this evidence by $(74 \%)$ of the studied couples take their knowledge about ART through media only (24\%) through nurses .More than half of infertile couple informed through media and disagree with Farnaz \& Mina (2005 ).About (73\%) of infertile couple knowledge from health care provider.

So establishment of continuous education program for the nurses in infertility outpatient clinics should be expansible.

\section{Conclusion}

Based on these findings of the present study it was concluded that, $(81 \%)$ of the studied couples had poor knowledge about ART, while (85)\% of these couples had positive attitude toward ART .

\section{Recommendations}

It was recommended that,

- Establishment of continuous education program for couples in infertility outpatient clinics to provide education about ART by using booklet and illustrated pamphlets for each type for those who can't read and write.

- Special emphasis needs to be placed on directing IVF patients toward correct information and healthy practices and helping them seek medical advice as their only preference for treatment

- Encourage more researches about couples infertility.

- Ample reproductive counseling should be available to all couples coming for treatments. The information given to patients should be evidence based.

\section{References}

1. Abolfotouh A., Mostafe, Abdullah A., Alabdrabalnabi, Rehab B., Albacker, Umar, A., Al-Jughaiman, \& Samar N., Hassan (2012): Knowledge, attitude, and practices of infertility among Saudi couples .Saudi Med J vol.30 (4) : 461- 464

2. Ali, Sumera Raafay Sophie, Ayesha M., Imam, Faisal I., Khan, Syed F., Ali, Annum Shaikh \& Syed Farid-ul-Hasnain (2011): Knowledge, perceptions and myths regarding infertility among selected adult population in Pakistan: a cross-sectional study, BMC Public Health 11:760.

3. American Society for Reproductive Medicine, 2012): Diagnostic evaluation of the infertile female: a committee opinion. Fertil Steril ;98:302-307.

4. Bunting L., Boivin J., (2008): Knowledge about infertility risk factors, fertility myths and illusory benefits of healthy habits in young people. Hum Reprod. 2008;23(8):1858-1864.

5. Centers for Disease Control \& Prevention (2014): Infertility and Impaired Fecundity in the United States 1982-2010: Data From the National Survey of Family Growth. Available at http://www.cdc.gov/nchs/data/nhsr/nhsr067.pdf

6. Farnaz Sohrabvand M., Mina Jafarabadi M., (2005): Knowledge and attitude of infertile couples about assisted reproductive technology. Iranian journal of Reproductive Medicine 2005 Vol 3: 90-94

7. Fido A., (2004): Emotional distress in infertile women in Kuwait. Int $\mathbf{J}$ Fertil Womens Med;49(1):24-28. [PubMed].

8. Gundla S., (2012): A study to describe the knowledge and attitude of infertile women 
regarding assisted reproductive techniques (ART) at a selected infertility clinic ,Bangalore, India 2011. Asian Journal of Nursing Education \&Research , January-March; Vol 1:6-8.Human Reproduction, 19(4):960-967

9. Inhorn M., (2006): Making Muslim babies: IVF and gamete donation in Sunni versus Shi'a Islam. Cult Med Psychiatry 2006, 30(4):427-450.

10. Shapira, S.., \& Dolan, S., (2006): Genetic risks to the mother and the infant: Assessment, counseling, and management. Maternal and Child Health Journal 10(7), 143-146. Retrieved May 28, 2007, from PubMed Central database

11. Sallam H., (2013): Infertility in Egypt: Science, Myth, and Religion. http://www.iaac.ca/fr/infertility-in-egyptscience-myth-and-religion

12. Sones H.,\& Cohen J., (2007): statement of general purpose. Fertil steril; 87(suppli)

13. Stephen J., Genuis, M., FRCSC, Dabog, WeiChing Chang, PhD, Shelagh K., Genuis, Bscot. (1993): Public attitudes in Edmonton toward assisted reproductive technology. Canadian medical association journal;vol 149(2).

14. Zegers-Hochschild F., Adamson, G., de Mouzon, J., Ishihara, O., Mansour, R., Nygren, K., Sullivan, E., van der Poel, S., on behalf of Icmart \& who (2009): "The International Committee for Monitoring Assisted Reproductive Technology (ICMART) and the World Health Organization (WHO) Revised Glossary on ART Terminology, Volume 24, No.11 pp. 2683-2687. 